\title{
Desenvolvimento de brinquedos infantis para espaços públicos com foco no imaginário local para o município de Paragominas-PA
}

Development of toys for public spaces with focus on the collective imaginary in the city of Paragominas-PA

AZEVEDO, Thiago Guimarães I Mestre em Artes

Universidade do Estado do Pará - UEPA I azevedo_thiago@yahoo.com.br

FERREIRA, Antonio Victor Lima I Bacharel em Design

Universidade do Estado do Pará - UEPA I avictorlf0106@outlook.com

SILVA, Michele Silva e

Universidade do Estado do Pará - UEPA I michele.kairos@gmail.com

ANDRADE, Rafael de Alencar

Universidade do Estado do Pará - UEPA I rafael.andrade1992@gmail.com

CAVALCANTE, Rodrigo Augusto de Sousa I Bacharel em Design

Universidade do Estado do Pará - UEPA I rodrigo_171192@hotmail.com

\begin{abstract}
Resumo
O presente artigo visa apresentar o resultado final do projeto financiado pelo Programa de Iniciação Tecnológica da Universidade do Estado do Pará. Ele visa refletir a participação do design no âmbito das cidades, principalmente no que se refere à compreensão do universo sustentável em Paragominas/PA. Esta cidade representa a mudança na sua postura de pensar o debate ambiental através de políticas públicas, por meio do Programa Municípios Verdes, entretanto, cabe indagar o que há dessa questão no imaginário coletivo e que represente visualmente nos espaços públicos. Dessa feita, desenvolver produtos para esses espaços, não requer somente aspectos formais e pesquisa de materiais, mas estimular o debate participativo do design no que se refere à política pública. Como método de desenvolvimento da pesquisa, se utilizará do Discurso do Sujeito Coletivo para identificação de imaginários e metodologia projetuais que permeiam a atividade do design.
\end{abstract}

Palavras-chave: Município Verde. Mobiliário Urbano. Espaço Público.

\section{Abstract}

This study presents the final results of a project funded by the Technological Initiation Program of the State University of Pará. It aims to reflect the impact of design in cities, especially with regard to the understanding of the sustainable practices in Paragominas / PA. The city became a role model by changing its way of thinking the environmental issues through public policies, supported by the Green Municipalities Program. However, it is necessary to investigate what there is of this question in the collective imaginary that can be visually represented in public spaces. Thus, developing products for these spaces requires not only formal aspects and research of materials, but also depends on promoting the participatory design debate regarding public policies. As a method of research development, the Collective Subject Discourse will be used to identify imaginary and project requirements embodying the design activity.

Keywords: Green Town. Street Furniture. Public Space. 


\section{INTRODUC̣ÃO}

O presente artigo tem como objetivo apresentar o resultado do projeto financiado no Programa de Bolsa de Iniciação Tecnológica - PIBIT da Universidade do estado do Pará que discute a relação entre Design e Cidade que tem por título - DESENVOLVIMENTO DE BRINQUEDOS INFANTIS PARA ESPAÇOS PÚBLICOS COM FOCO NO IMAGINÁRIO LOCAL PARA O MUNICÍPIO DE PARAGOMINAS-PA. Isso se dá no âmbito do debate que se situa em torno do Programa Município Verde adotado pelo Governo Federal em Parceria com os Governos Estadual e Municipal aplicados no município de Paragominas-PA.

Observa-se que ao longo de seu desenvolvimento, o município de Paragominas ganhou ampla visibilidade por conta de suas transformações no seu espaço político e urbano, em virtude de sua luta contra o desmatamento, ao qual figurava entre as principais cidades que desmatavam no País e por conta disso, através do governo Federal em parceria com o governo Estadual e Municipal, várias ações foram realizadas para alterar esse quadro (ORTIZ, 2014), entre elas, a implantação do programa Município Verde, que segundo o site do projeto corresponde:

[...] combater o desmatamento no Estado, fortalecer a produção rural sustentável por meio de ações estratégicas de ordenamento ambiental e fundiário e também de gestão ambiental, com foco em pactos locais, no monitoramento do desmatamento, na implantação do Cadastro Ambiental Rural (CAR) e na estruturação da gestão ambiental dos municípios participantes. (MUNICÍPIO VERDES, 2015).

Com isso, nos últimos 15 anos o município alterou seu posicionamento nacional, tornando-se referência no que tange à política contra o desmatamento. Isso se reflete na forma como a cidade se reorganizou e dessa forma, seu espaço urbano sofreu profundas modificações, todavia, percebe-se que esse imaginário do município verde não é visível no que se refere a construção de referências imagéticas em seus ambientes públicos, tornando-se apenas algo do inconsciente coletivo marcado pela história e memória de seus pioneiros.

Dessa feita, o design possui um papel importante nessa discussão sobre sua interação com as cidades e principalmente nos debates atuais que envolvem questões de políticas públicas e de como elas podem interferir para fortalecer identidades, criar condições para desenvolvimento de turismo local e com isso, fomentar a geração de trabalho e renda.

Esta pesquisa situa como relevante ao universo do design no aprofundamento dos aspectos relacionados à busca de identificação dos imaginários que envolvem a relação das pessoas com as cidades, pesquisa de 
materiais, em virtude de se buscar alternativas sustentáveis para desenvolver produtos que dialoguem com o princípio da sustentabilidade e fomentar no universo do design a reflexão sobre o programa Município Verde e, de como este processo pode ser ampliado de modo que o design possa contribuir por intermédio de seu pensamento epistemológico e sistêmico.

Nesse sentido, de acordo com Paula (2006), há uma relação intrínseca entre a cidade e a universidade desde sua constituição no que se pode chamar de modernidade, neste aspecto, essa interação auxilia no seu desenvolvimento urbano e social.

O design como conhecimento que alia aspectos produtivos relacionados à adequação de objetos tangíveis aos indivíduos, contribui para que neste processo haja interação entre a Universidade e a cidade, visto que mediante estes objetos como linguagem, há como se proporcionar um diálogo simbólico através dos signos existentes em seus artefatos ou mobiliários, a fim de que, se alcance a integração entre o imaginário das cidades e o que ela apresenta em suas visualidades como uma forma de construção de identidades locais. Ou como afirma Bonsiepe (2011, p. 54): "A identidade não depende tanto do que cada um é ou tem, mas do que vive no imaginário das outras pessoas. Identidades pertencem ao mundo do l'imaginaire. Elas são artefatos de comunicação".

\section{DESENVOLVIMENTO}

O universo das cidades é um complexo, não apenas de ligações entre suas vias, estruturas arquitetônicas e espaços urbanos, mas redes de interação social, visto que são nelas em que se pode experimentar o processo de socialização, com isso, é necessário haver formas de interação entre indivíduos e seu espaço, para que se possibilite a construção das identidades.

Esses aspectos que envolvem as identidades nas cidades são fruto também de um olhar sobre os imaginários que se cercam em torno dela. Por imaginário, de acordo com Durand (1998) se compreende como uma resposta a questões relacionadas à existência humana, em virtude de experiências "negativas" no decorrer do tempo. No caso de Paragominas, a sua história representa uma trajetória marcada por aspectos de triunfalismo diante de sua imagem construída sobre o desmatamento, que vai desde seus pioneiros em sua fundação ao de sua re-construção até ser reconhecido como Município Verde.

Ao estabelecer esse conceito, Durand (1998) o divide em três regimes: Heroico; Místico; Sintético. Eles representam a forma como essas perspectivas são construídas, nesse sentido, ao observar sobre como se constitui o imaginário do município de Paragominas, na fala das pessoas que residem no local, há um tom heroico na forma de pensar a cidade, ao que se refere aos seus pioneiros, principalmente Célio Miranda, seu fundador nos anos 50 e do ex-prefeito 
Adnan Demachki, este último como responsável por tirar o município de seu quadro negativo de desmatamento e incluí-lo à lista de exemplos de municípios com selo verde.

Entretanto, ao verificar a pesquisa de campo, esse imaginário já começa a ser repensado por uma parcela mais nova da população, principalmente as que frequentam os espaços públicos como as praças do município, dessa feita, por meio desses resultados, percebe-se que há uma falta de referenciais simbólicos que pontuem marcos históricos do município.

Com isso, de acordo com Laplantine e Trindade (2003), o imaginário se utiliza do simbólico para construção de signos que representem aspectos relativos a imagens de uma cultura, neste sentido, está presente em toda a vida social, visto que são através das experiências do cotidiano, nas interações sociais que são construídos essas relações que marcam as percepções fenomenológicas da cultura. Isso reflete a forma como as cidades podem ser construídas no que se refere à forma de pensar e agir de um grupo social.

Entretanto, apesar desse esforço em preservar essa imagem e seu imaginário do município verde em Paragominas, vale indagar o que há desse pensamento nos espaços urbanos que compõe o município e como a população atual absorve essa imagem que a cerca a partir desses ambientes, visto que ao efetivar a pesquisa de campo, pouco se percebe desses referenciais simbólicos em seu mobiliário urbano.

O que se nota é que a caracterização dessa mudança na imagem urbana do município se concentra com maior evidência em dois lugares, o espaço Lago Verde, ambiente modificado para agregar pista de cooper, pedalinhos, academia ao ar livre, brinquedos infantis e criadouro de peixes, e o Parque Ambiental, local de preservação ambiental, cenário para visitação e atividades educacionais.

Todavia, mesmo com esses espaços como marcos de modificação urbana, ao se pensar os brinquedos infantis, não seguem a lógica ambiental a qual figura o município, além dos outros lugares existentes. Há na cidade pelo menos 36 praças em funcionamento e de acordo com os dados do IBGE (2015) a cidade de Paragominas possui cerca de 105.417 habitantes, as crianças matriculadas no ensino Fundamental em 2012 eram num número de 22.472 e em creches eram de 34.908. Dessa forma, estima-se que o número de crianças residentes em Paragominas é de pelo menos 57.380, com isso, percebe-se que há uma incidência significativa de crianças no município.

Ao refletir sobre esses aspectos que envolvem a relação design e valorização cultural territorial, Krucken (2009) enfatiza que os produtos locais são manifestações culturais, ou seja, expressam a identidade de um grupo social e que através da relação de consumo servem como mecanismos de divulgação e valorização, dessa forma, através dessa interação entre o design e 
das políticas públicas que foquem no turismo e atividades culturais, há como se desenvolver a geração de trabalho e renda e com isso a sociedade local como um todo é beneficiada com isso.

\begin{abstract}
Os produtos locais são manifestações culturais fortemente relacionadas com o território e a comunidade que os gerou. Esses produtos são os resultados de uma rede, tecida ao longo do tempo, que envolve recursos da biodiversidade, modos tradicionais de produção, costumes e também hábitos de consumo. A condição de produto ligado ao território e à sociedade nos quais surgiu é representada no conceito de terroir [...] (KRUCKEN, 2009, p. 17)
\end{abstract}

Para ela, o design tem papel preponderante no que se refere à valorização da cultura material e imaterial por sua forma de compreender o processo produtivo e desenvolvê-lo de forma sistêmica, aliando a uma forma de pensar interdisciplinar que segundo Krucken (2009), pode ser agrupada em três linhas:

1. Promover a qualidade dos produtos, dos territórios, dos processos de fabricação;

2. Apoiar a comunicação, aproximando consumidores e produtores e intensificando as relações territoriais;

3. Apoiar o desenvolvimento de arranjos produtivos e cadeias de valor sustentáveis, visando ao fortalecimento de micro e pequenas empresas.

No caso de Paragominas, essa valorização territorial está em primeiramente detectar o imaginário da população, visto que há uma confluência de identidades, tornando-a híbrida, de acordo como expressa Canclini (2000). Dessa forma, o que há de comum nesta busca pelo imaginário coletivo é a perspectiva do Município Verde, ou seja, de Paragominas ser reconhecida como cidade sustentável.

\title{
2.1 O Design e o Programa "Municípios Verdes"
}

De acordo com o Imazon (2015), o plano "Municípios Verdes" foi uma série de medidas realizadas pelo governo federal entre 2007 e 2009 como forma de combater o desmatamento na Amazônia. E conforme o decreto 6.321 e seus atos administrativos, a medida recorria à municipalização do combate ao desmatamento, por intermédio de restrição ao crédito de produtores irregulares. E segundo o processo, a cadeia produtiva foi responsabilizada pelo desmatamento ilegal e foi disponibilizada à sociedade a lista dos infratores e a dos municípios críticos do desmatamento, ao qual Paragominas figurava entre as que mais depredavam a floresta. 
As ações de fiscalização dessa operação focaram nos municípios críticos do desmatamento, que até 2010 já somavam 43. Eles sofreram maiores restrições para acessar crédito, e seus produtores e empresas tiveram a imagem comercial negativamente afetada. Isso levou alguns municípios a buscarem um novo modelo de desenvolvimento. Paragominas, no Pará (2008), foi um dos primeiros municípios[1] a implantar o conceito de "Município Verde". Esta iniciativa permitiu a Paragominas a condição de ser o primeiro município a sair da lista de municípios críticos. Em abril de 2011, o município de Querência (Mato Grosso) foi o segundo a sair da lista. Como resultado, em abril de 2011, o número de municípios críticos caiu de 43 para 41.

Paragominas foi mais adiante e começou a implantar também mudanças em sua base produtiva. Sua experiência no processo de transição de um modelo baseado em atividades predatórias para o sustentável tem atraído interesse de outros municípios da região. Além disso, no Pará, sob a liderança do governo do Estado, foi criado, em março de 2011, o Programa Municípios Verdes. Esse programa tem como objetivos apoiar a redução do desmatamento e degradação florestal, promover uma nova economia rural com base na floresta e no uso intensivo da agropecuária e melhorar a governança local criando legalidade e sustentabilidade. (IMAZON, 2015).

Dessa feita, o conceito de município verde abrange atividades produtivas sustentáveis com baixa emissão de carbono e alta responsabilidade social e ambiental. Segundo o Imazon, na Amazônia, o município verde estimula: (i) a governança local para ampla gestão municipal do meio ambiente; (ii) o manejo florestal; (iii) a intensificação da agropecuária e do reflorestamento; (iv) o uso sustentável e a conservação das funções ecológicas das florestas e remanescentes; e (v) a recuperação de Áreas de Preservação Permanente (APP) e Áreas de Reserva Legal (ARL). Além disso, o município define e executa ações de monitoramento local das atividades produtivas e da pressão sobre a floresta como medida efetiva de combate ao desmatamento e promove a inserção de todos os produtores no Cadastro Ambiental Rural (CAR) e no Licenciamento Ambiental Rural (LAR). Com isso, ele cria bases para a segurança jurídica, o que permite atrair investimentos de qualidade.

Nesse sentido, ao refletir sobre a dimensão que abrange o conceito Município Verde, é necessário expandi-lo para torná-lo algo que faça parte do cotidiano da cidade, como modelo mais amplo de sustentabilidade que envolva também, não apenas as regiões rurais, todavia, também em função do que se entende em seu espaço urbano. 


\subsection{Mobiliário Urbano no Desenvolvimento Imaginário de uma Identidade Local}

Segundo Pereira (2002), a cidade não é percebida apenas no que se refere aos seus objetos que ornamentam seus espaços, mas por tudo que compõe o projeto de cidade, no caso desta pesquisa, o mobiliário é incorporado como um fator fundamental de percepção dos imaginários da cidade.

É importante ter claro que, no cenário atual, as cidades concorrem por recursos econômicos, muitas vezes advindos da atividade turística ou empresarial. De acordo com Helbrecht (1991), o turismo é significativamente influenciado pela imagem que a cidade remete em forma de imaginário. Dessa forma, a cidade possui em si uma cadeia de significações que estão relacionadas à sua cultura e estrutura física por meio de seu mobiliário e objetos que a compõe.

O mobiliário urbano está relacionado ao desenvolvimento das cidades, pois para Lerner (2003, p. 83) "identidade, autoestima, sentimento de pertencer, tudo tem a ver com os pontos de referência que uma pessoa possui em relação à sua cidade". Vieira (2011) defende a formação da imagem do espaço urbano, principalmente quando posicionada positivamente, podem gerar atratividade. Isso ocorre por que torna- se possível evitar que "uma rua seja mais uma rua, que um bairro seja mais um bairro, que uma cidade seja mais uma cidade" (PEREIRA, 2002, p. 104).

A identidade é algo que se forma ao longo dos anos, que acompanha e se transforma junto com o sujeito. Todas as interferências culturais e aprendizados são agregados nesta identidade, modificando-a. Hall (2006) aponta que essas identidades possuem uma construção imaginária e que sempre está em processo de construção, visto que ela é incompleta.

O mobiliário urbano possui uma presença física no espaço público que se relaciona ao ambiente construído de uma cidade tais como as edificações, vias, calçadas e praças, mas também com o clima, a cultura, os comportamentos e as percepções que as pessoas têm a respeito de sua cidade, e que, numa relação sistêmica, gera uma imagem urbana característica. Fleming (2007) destaca que por conta do processo de globalização e a consequente homogeinização estética existente no mobiliário, há uma caracterização mais genérica do mobiliário urbano e com isso, há uma perda de identidade a partir desses produtos nos espaços públicos. Essa prática não promove uma diferenciação do espaço urbano através do mobiliário urbano, que poderia ser benéfica como estratégia de Marketing para cidade.

Considerar apenas os aspectos técnicos produtivos e os parâmetros ergonômicos no design do mobiliário urbano é uma visão reducionista e pragmática do designer que deve ser evitada e que pode ter como consequência 
um produto tecnicamente bem resolvido, mas que, por outro lado, não incorpora o ponto de vista do usuário nem reflete suas aspirações com relação a sua identificação com o objeto.

Desse modo, o mobiliário urbano poderá via a ser compreendido como o elemento que estrutura funcionalmente e atribui qualidade ao espaço público urbano, contribuindo para que este possa ser efetivamente usado e usufruído por todos os cidadãos, proporcionando maior integração entre o ambiente construído e o homem, além de promover uma interação social entre os usuários que utilizam determinado lugar para realizarem suas atividades urbanas e mostrar também como uma identidade local possa influenciar no comportamento do mobiliário urbano.

\section{METODOLOGIA}

Para realização desta pesquisa, o desdobramento metodológico seguiu em três vias: A primeira está no que confere aos aspectos relacionados à pesquisa bibliográfica, para identificar o que há de registros sobre a história do município de Paragominas, bem como suas transformações sócio-políticas até a formação do que se chama atualmente - Município Verde. Nessa etapa também foi desenvolvido pesquisas relacionadas ao ato de brincar e como se estrutura o conceito de playground, bem como as NBRs relacionadas a constituição de Playground e acessibilidade nesses espaços (ASSOCIAÇÃO BRASILEIRA DE NORMAS TÉCNICAS, 1999, 2012, 2015).

A segunda etapa metodológica da pesquisa se deu através da pesquisa de campo, esta foi realizada em duas frentes. A primeira foi através da visitação dos espaços públicos no município de Paragominas. Foram selecionada 5 praças com maior fluxo de movimentação para realização da pesquisa de campo. As visitações ocorreram em 6 sextas e 6 finais de semana, visto que eram os dias que apresentaram maior índice de presença de crianças e adultos nos locais. Nestas visitas procurou-se observar a forma de uso dos brinquedos existentes e através de aplicação de formulários com os pais das crianças para identificar preferências e elementos simbólicos que podem se identificar com o município, a amostragem da pesquisa foi de 150 pais e mães no período de realização da pesquisa de campo nos espaços públicos que ocorreu nos meses de Janeiro e Fevereiro de 2016.

Para contextualizar a questão da população de Paragominas e seu espaço público. Atualmente a cidade possui 36 praças com área de lazer, segundo o coordenador da Secretária Municipal de Urbanismo, através de uma conversa telefônica, contando com praças principais e pracinhas como rotatórias para bairros, além das áreas de preservação ambiental que possuem espaço para brinquedos públicos como o Parque Ambiental e o Lago Verde, dessas, 11 são mais frequentadas por estarem em melhores estados de conservação. De 
acordo com o IBGE (2015) a cidade possui cerca de 107.010 habitantes, tento uma estimativa de 26.503 crianças conforme dados de matrículas do IBGE de 2012, sem contar as crianças em creches.

A segunda etapa da pesquisa de campo ocorreu em duas escolas municipais de Paragominas (E.M.E.F Raimundo Nonato Sobrinho e E.M.E.F. Sonia Tereza). Para a realização dessa parte, foi utilizado o método de Mapa Mental que segundo Shitsuka, Silveira e Shitsuka (2011) trabalhando com o conceito de Buzan, define como diagramas que auxiliam na estruturação do pensamento humano que são utilizados de forma criativa e são utilizadas palavras, figuras, sons ou cores para facilitar a compreensão de uma dada ideia.

Na pesquisa de campo nas escolas priorizou-se abordar as crianças de 6 a 9 anos das turmas de $1^{\circ}, 2^{\circ}$ e $3^{\circ}$ ano do Ensino Fundamental I, visto que a partir das visitas nos espaços selecionados, essa faixa etária era a que mais utilizava os brinquedos existentes nos locais. Para se obter informações das crianças, foi criada uma dinâmica através do uso de papel em branco e lápis de cor e era perguntado sobre o que gostavam mais do município, o que mais fazia lembrar dele, bem como do que mais gostavam de brincar quando estavam nas praças da cidade.

Por meio de seus desenhos, foi possível extrair elementos visuais como formas, cores, elementos simbólicos e a estruturação do conceito mais forte que relacionava o imaginário coletivo ao município. A partir dos dados obtidos nas praças (pais) e nas escolas (crianças), chegou-se a dois diagramas, o primeiro está relacionado aos pais e o segundo a partir dos desenhos das crianças e a partir desses diagramas se puderam desenvolver um painel semântico que auxiliou na identificação simbólica das respostas:

Figura 1 - Mapa mental em relação ao imaginário dos pais

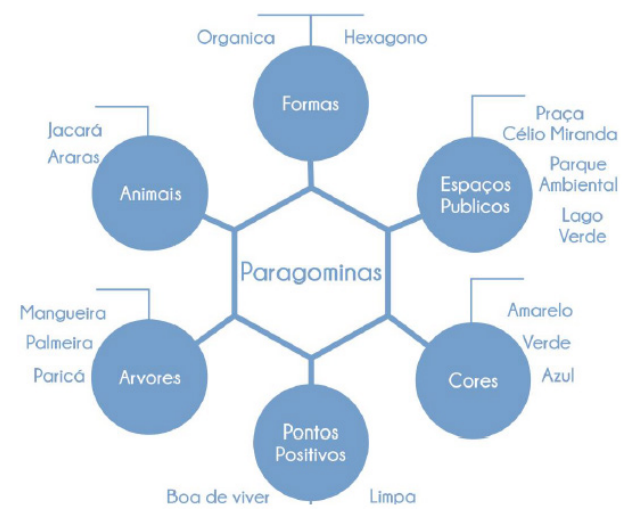

Fonte: Produzido pelos autores 
Figura 2 - Mapa mental em relação ao imaginário dos crianças

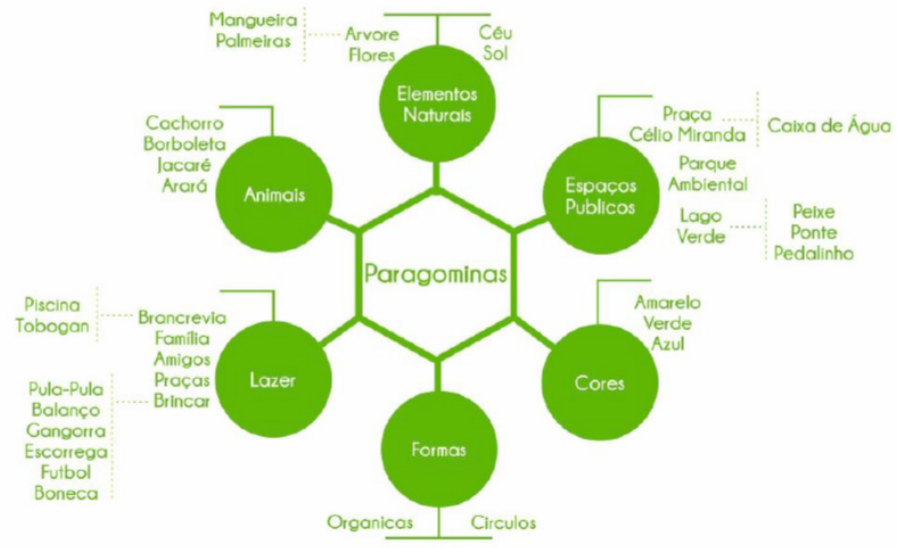

Fonte: Produzido pelos autores

Figura 3 - Painel semântico sobre o município de Paragominas

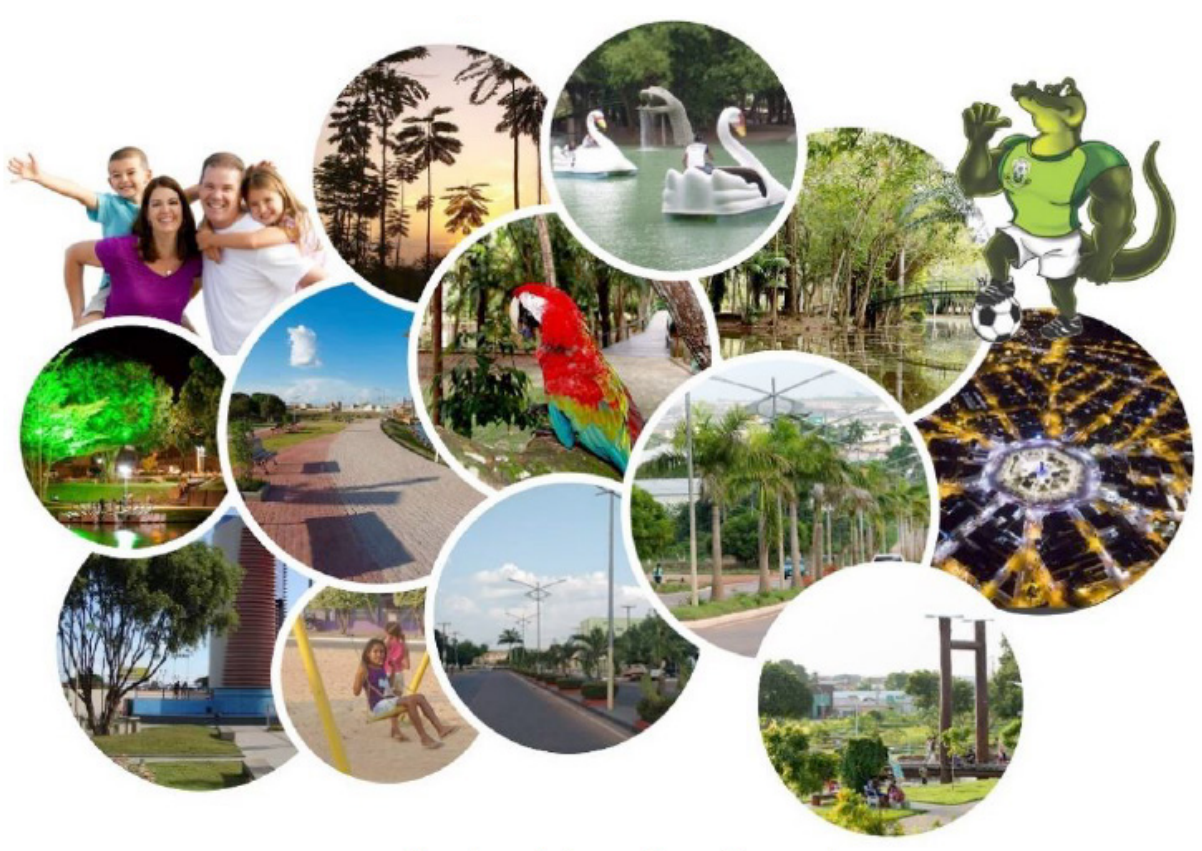

Fonte: Produzido pelos autores

Para a terceira etapa, relacionada ao desenvolvimento do projeto em si, trabalhou-se com as metodologias de Löbach (2001) relacionadas às análises da tarefa e da função e da pesquisa de materiais e utilização das normas. A partir do levantamento dos dados e da construção do painel semântico, foi realizado o mapeamento e análise dos brinquedos existentes nos espaços pesquisados e também uma busca de produtos similares para identificar diferenciais e com isso elaborar os conceitos através de desenhos e desenvolvimento da estrutura para análise de materiais, bem como adequação do produto para atender questões de acessibilidade para cadeirantes por meio da um balanço adaptado de acordo com a NBR 9050, Associação Brasileira de Normas Técnicas (2015). 


\section{RESULTADOS E DISCUSSÕES}

\subsection{Conceito}

O playground a ser desenvolvido vai abarcar os principais elementos identificados pelos grupos citados acima, que estão presentes no painel semântico gerado a partir da análise de dados, dando maior ênfase nos animais identificados para atrair as crianças, e trabalhando principalmente na busca de materiais presentes na região e de fácil e de fácil acesso para compor o brinquedo, com características sustentáveis.

O brinquedo vai apresentar aspecto rústico e natural, com poucas partes pintadas destacando a naturalidade da madeira, enaltecendo um clima aventureiro. E assim dialogar com a cidade, que enfrentou conflitos para se tornar um município de exemplo com crescimento sustentável, além de remeter a alguns mobiliários e a ponte que estão no Lago Verde, com o aspecto natural da madeira.

A ideia é que o playground a ser gerado alcance todos os espaços públicos da cidade, para que a mesma promova a sustentabilidade por todos os cantos do município, o que é evidente apenas em locais estratégicos que tem maior visitação. Além de carregar elementos característicos de Paragominas, com a identidade própria e deixar de utilizar os brinquedos públicos de formas e materiais genéricos, os quais já não são tão atrativos para as crianças.

Um brinquedo de uso coletivo aliado às funções prática, estéticas e simbólicas, para assim proporcionar uma melhor experiência para as crianças ao brincarem em um playground público. O playground terá em sua composição, plataforma, escorrega, balanço, balanço acessível, gangorra, ponte e rede de corda, assim, permitindo que várias crianças brinquem ao mesmo tempo e proporcionando uma maior interação entre elas. O brinquedo vai promover para as crianças diversão, conhecimento e alegria, com atividades que contribuem com seu crescimento saudável e com a consciência sustentável.

Para titular o playground, foi escolhido um nome de origem TupiGuarani, "Orube", que expressa alegria, risos e felicidade, o que remete a muitos sentidos, principalmente ao que é percebido pela visão dos moradores da cidade que foi diagnosticado pelos formulários aplicados, que Paragominas é um município bom para viver e que esse mesmo conceito e transmitido pelas mídias da prefeitura, além de representar a essência do brinquedo que é proporcionar sentimentos positivos para as crianças.

\subsection{Desenvolvimento do produto}

Um dos elementos chaves para identificar um dos elementos marcos do município é a Caixa D'Água que se situa na principal praça de Paragominas

Projética, Londrina, v.8, n.2, p. 67-82, Jul./Dez. 2017 
que recebe o nome de seu fundador, Praça Célio Miranda, ela se localiza no eixo central de um conjunto de hexágonos que liga a várias ruas e outras praças próximas. Além da presença de dois animais, que segundo as respostas coletadas, representam o município, a Arara vermelha (presentes como mascotes da reserva ambiental localizada no bairro Promissão I) e o Jacaré (mascote do time de futebol do município, o PFC - Paragominas Futebol Clube). As cores mais evidentes, tanto nas respostas dos pais, quanto nos desenhos das crianças, foram cores quentes, além do verde e azul, que representam o imaginário do Município Verde e fazem parte das cores da bandeira.

Figura 4 - Esboço final do produto

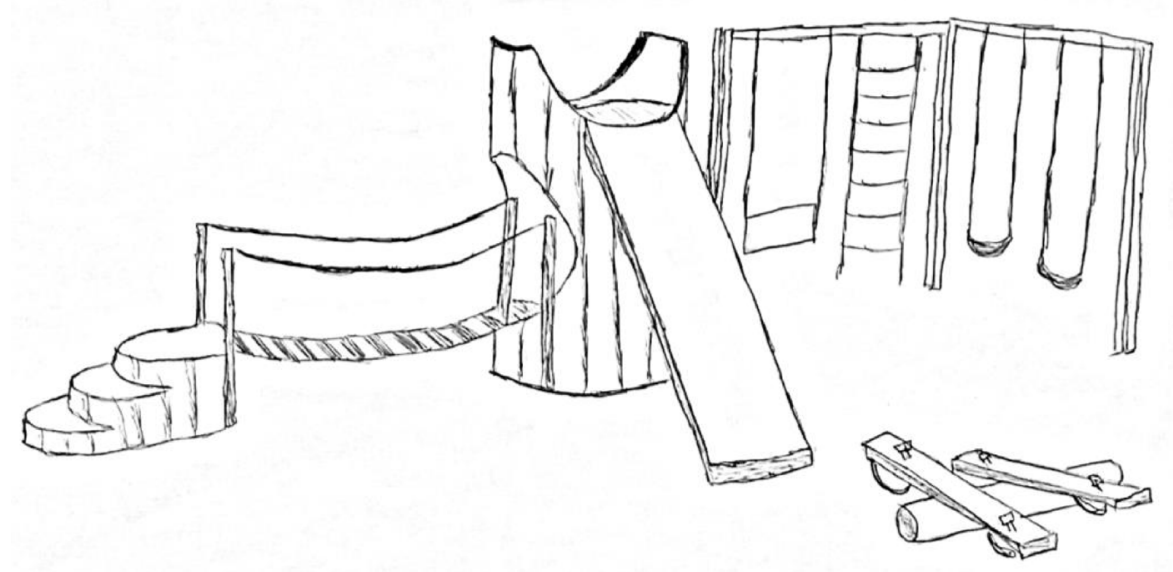

Fonte: Produzido pelos autores

A partir da construção do conceito e do desenvolvimento dos desenhos técnicos, foi elaborada uma maquete eletrônica para apresentar o projeto. Optouse o uso de madeira, pois na Secretaria do Meio Ambiente, há muitas toras que foram apreendidas por terem sido extraídas ilegalmente e podem ser utilizadas no próprio município e pneus reutilizados, por se encontrar grande número de borracharias que atendem muitos caminhões e há um grande volume de pneus descartados. As cores serão utilizadas como detalhes nos brinquedos bem como os animais estão presentes de forma estilizada como peças decorativas, com exceção do jacaré que representa uma peça de alavanca da gangorra como pode se ver na imagem abaixo. 


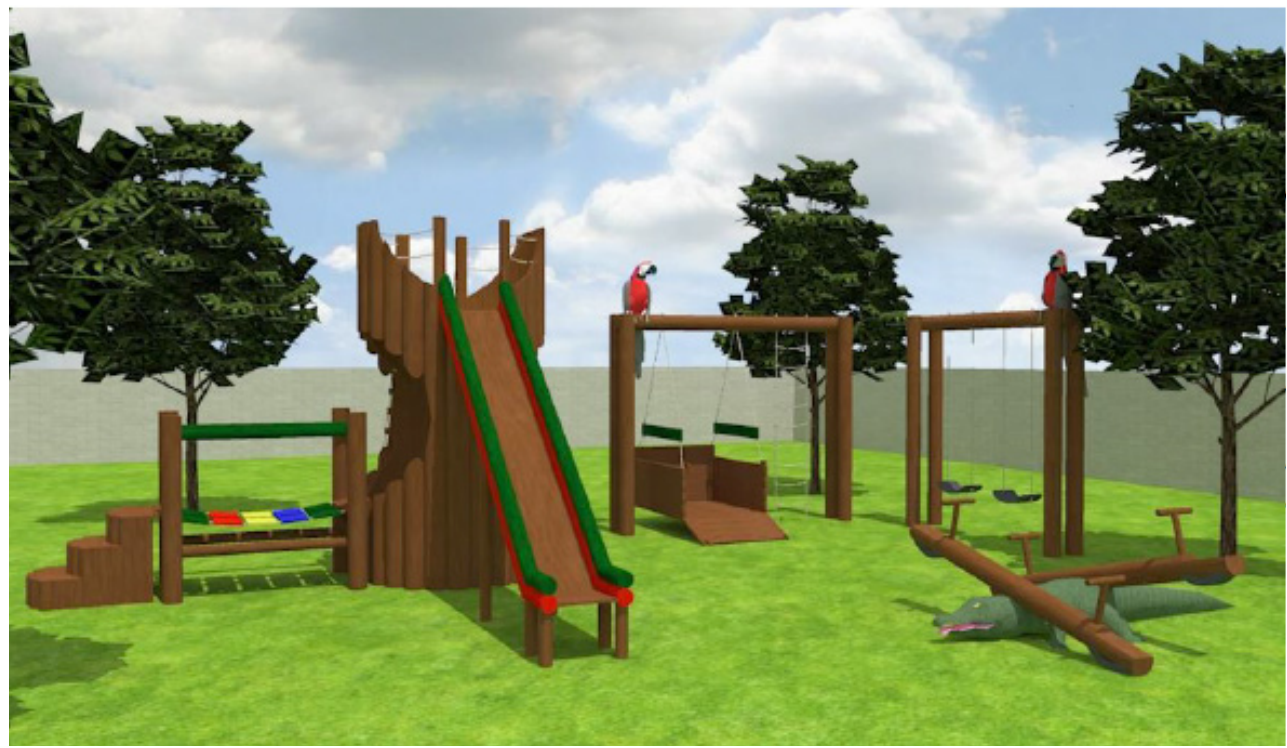

Fonte: Produzido pelos autores

\section{CONSIDERAC̣ÕES FINAIS}

Como objetivo, a pesquisa resultou no desenvolvimento de um playground para os espaços públicos na cidade de Paragominas-PA, tendo como principal finalidade passar por meio do ato de brincar uma nova experiência para as crianças, conduzindo através dos brinquedos a identidade da cidade na pesquisa, de forma simples, pratica e divertida.

Este projeto atua também como incentivo para a diversão em espaços públicos e ao ar livre que proporciona a interação entre outras crianças, já que com o avanço da tecnologia os pequenos passam a brincar fora de suas casas dando maior atenção aos jogos digitais, dessa forma diminui o contato com o meio ambiente e a interação entre elas.

Considerando o objetivo proposto pela pesquisa, se tornou necessária o estudo bibliográfico de diversas áreas, mostrando o design como meio interdisciplinar, para compreensão do problema e assim dá início o desenvolvimento do projeto, utilizando como base a metodologia de Löbach (2001), com o auxílio fundamental de ferramentas como o discurso do sujeito coletivo, mapa mental e brainstorming, para assim captar subsídios para o desenvolvimento do projeto.

A pesquisa é relevante para o entendimento da atuação do designer na cidade, quando este tem a função de solucionar problemas por meio de ferramentas funcionais. Neste caso foi desenvolvido um produto de mobiliário urbano com as características locais, e dessa forma compreender a sua importância, quando busca a valorização regional para ser expressa em elementos pela cidade. 
Com relação à pesquisa de materiais para a composição do playground, no qual o principal elemento é a madeira, propõe-se a utilização das madeiras que são apreendidas no município, que passam a ser do poder público, e os pneus que são descartados em borracharias da cidade.

É importante esclarecer que o brinquedo necessita ser prototipado e passar por alguns testes antes de ser implantado nos espaços públicos, para que sejam reforçados os estudos sobre a engenharia da estrutura do playground, pois o mesmo pode sofre alterações no decorrer do processo de implantação.

Notou-se ao decorrer do desenvolvimento do brinquedo, a necessidade de utilizar as medidas e seguir as recomendações que são indicadas pela NBR, para resultar em um produto final com êxito, em condições ergonômicas e seguras adequadas para os usuários.

\section{REFERÊNCIAS}

ASSOCIAÇÃO BRASILEIRA DE NORMAS TÉCNICAS. NBR 14350: segurança de brinquedos de playground. Rio de Janeiro, 1999. Parte 1, Requisitos e Métodos de Ensaio.

ASSOCIAÇÃO BRASILEIRA DE NORMAS TÉCNICAS. NBR 16071: playground. Rio de Janeiro, 2012.

ASSOCIAÇÃO BRASILEIRA DE NORMAS TÉCNICAS. NBR 9050: acessibilidade a edificações, mobiliários, espaço e equipamentos urbanos. Rio de Janeiro, 2015.

ASSOCIAÇÃO BRASILEIRA DE NORMAS TÉCNICAS. NBR 9283 - Mobiliário Urbano - Classificação de 1986. Rio de Janeiro: ABNT, 1986.

ASSOCIAÇÃO BRASILEIRA DE NORMAS TÉCNICAS. NBR 9284 Equipamento Urbano - Classificação de 1986. Rio de Janeiro: ABNT, 1986.

BONSIEPE, Gui. Design, cultura e sociedade. São Paulo: Blucher, 2011.

CANCLINI, Nestor García. Culturas híbridas. 3. ed. São Paulo: EDUSP, 2000.

DURAND, Gilbert. O imaginário: ensaio acerca das ciências e da filosofia da imagem. Rio de Janeiro: DIFEL, 1998. 
FLEMING, Ronald Lee. The art of placemaking: interpreting community through public art and urban design. London: Merrell, 2007.

HALL, Stuart. Identidade cultural na pós-modernidade. Rio de Janeiro: DP \& A, 2006.

HELBRECHT, Ilse. Das ende der Gestaltbarkeit? Zu Funktionswandel und Zukunftsperspektiven räumlicher Planung. Oldenburg: Bibliotheks- u, 1991. (Wahrnehmungsgeographische Studien Zur Regionalentwicklung, h. 10). IBGE. Cidades@. Disponível em: <http://cidades.ibge.gov.br/xtras/perfil. php?codmun=150550>. Acesso em: 4 jun. 2015.

IMAZON. Instituto do Homem e Meio Ambiente da Amazônia. Municípios verdes: caminhos para a sustentabilidade. Disponível em <http://imazon.org. $\mathrm{br} /$ municipios-verdes-caminhos-para-a-sustentabilidade/>. Acesso em $05 \mathrm{de}$ junho de 2015

KRUCKEN, Lia. Design e território: valorização de identidades e produtos locais. São Paulo: Studio Nobel, 2009.

LAPLANTINE, François; TRINDADE, Liana S. O que é imaginário. São Paulo: Brasiliense, 2003.

LERNER, Joshua. Acupuntura urbana. Rio de Janeiro: Record, 2003.

LÖBACH, Bernd. Design Industrial: bases para a configuração dos produtos industriais. São Paulo: E. Blücher, 2001.

MUNICÍPIOS verdes. Disponível em: <http://municipiosverdes.com.br/ pages/ quem_somos>. Acesso em: 23 maio 2015.

ORTIZ, Fabíola. A história do município que saiu da lista negra dos maiores desmatadores. 2014. Disponível em <http://www.oeco.org.br/ reportagens/28764-a-historia-do-municipio-que-saiu-da-lista-negra-dosmaiores-desmatadores>. Acesso em: 23 maio 2015.

PAULA, João Antônio de. A cidade e a universidade. In: BRANDÃO, Carlos Antônio Leite. As cidades da cidade. Belo Horizonte: Ed. da UFMG, 2006.

PEREIRA, Cristóvão Valente. Mobiliário urbano: abordagem e reflexão. Dissertação. (Mestrado em Design Urbano) - Universidade de Barcelona, Barcelona, 2002. 
PIAGET, Jean. A formação do símbolo: imitação, jogo e sonho, imagem e apresentação. 3. ed. Rio de Janeiro: Zahar, 1978.

SHITSUKA, Ricardo; SILVEIRA, Ismar Frango; SHITSUKA, Dorlivete Moreira. Comparação entre as ferramentas ontologia, mapas mentais e mapas conceituais na representação de conceitos em matriz curricular de curso de graduação. CRB-8 Digital, São Paulo, v. 4, n. 1, p. 2-10, abr. 2011.

VIEIRA, Maytê. Imaginário, imaginação social e seus símbolos. 2011. Disponível em: <http://www.mitoseimaginario.com.br/2011/06/imaginarioimaginacao-social-e-seus.html>. Acesso em: 5 set. 2016. 